\title{
Methotrexate-Associated Burkitt Lymphoma
}

National Cancer Institute

\section{Source}

National Cancer Institute. Methotrexate-Associated Burkitt Lymphoma. NCI Thesaurus.

Code C7255.

A Burkitt lymphoma that develops in patients who are immunosuppressed with methotrexate. 